\title{
URAL-CASPIAN REGION AS A HISTORICAL AND GEOGRAPHICAL PHENOMENON (XVI - THE BEGINNING OF THE XX CENTURY)
}

(C) 2017

\author{
Lyubichankovskiy Sergey Valentinovich, doctor of historical sciences, head of Russian History Department \\ Orenburg State Pedagogical University (Orenburg, Russian Federation) \\ Lyubichankovskiy Alexey Valentinovich, candidate of geographical sciences, researcher, \\ associate professor of Geography and Region Studies Department \\ Orenburg State University, Steppe Institute of Russian Academy of Sciences (Orenburg, Russian Federation)
}

Abstract. This paper deals with cross-disciplinary historical and geographical research. The Ural-Caspian Region existing from the 16th century to the beginning of the 20th century is its main focus. The Assessment of new lands inclusion in the Russian civilization is carried out. The authors analyze the Ural-Caspian Region through assessment of dynamics of its cultural landscapes. The social processes happening in the region are characterized. The authors suggest considering the Ural-Caspian Region as a frontier, existing from the 16th century to the beginning of the 20th century. Ethno cultural space structure mosaicity, original culture of the Cossacks and the zone with special social conditions were characteristics of the Russian and Nogai cultures assimilation at the early stage of the development. The Orenburg Region with its «creeping-away» regional identity is the only outlier of the Ural-Caspian Region. In its population historical memory it is possible to find five spatial images of the Orenburg Region: «base to Central Asia», «citadel of "civilization"», «testing ground for reforms», «operation object with huge resources» and «the deaf province».

Keywords: frontier; cultural landscapes; Ural-Caspian Region; development vector; nomad model; historical and geographical characteristic; civilization; Nogai Horde; assimilation; Orenburg Cossacks; ethno cultural space; regional identity.

УДК 94(410)

\section{ИСТОРИЧЕСКИЕ РОМАНЫ ВАЛЬТЕРА СКОТТА - СУБСТАНЦИАЛЬНЫЙ ФАКТОР ФОРМИРОВАНИЯ ШОТЛАНДСКОЙ НАЦИОНАЛЬНОЙ ИДЕНТИЧНОСТИ НА РУБЕЖЕ ХVIII-XIX ВЕКОВ} (C) 2017

Федорова Татьяна Александровна, аспирант кафедры всеобеей истории, права и методики преподавания Самарский государственный соџиально-педагогический университет (2. Самара, Российская Федераџия)

Аннотация. В данной статье рассматривается влияние исторических романов Вальтера Скотта на формирование национальной идентичности Шотландии на рубеже XVIII - начала XIX века. В свете современной геополитической ситуации, учитывая нарастающую волну сепаратизма, актуальность исследования процесса формирования национальной идентичности трудно переоценить. В статье анализируются исторические предпосылки формирования национального самосознания шотландцев, рассматриваются характерные особенности историко-культурного развития региона. По мнению автора, немаловажное значение в преодолении национальной разобщенности как Шотландии, так и Британии в целом имели работы Джеймса Макферсона и епископа Перси. Особое внимание обращается на роль сэра Уолтера Скотта в процессе национального возрождения Шотландии. Такие романы, как «Уэверли», «Пуритане», «Роб Рой», познакомили широкую публику с ментальным базисом шотландского народа. Раскрыв для широкого круга читателей особенности национального характера, религиозные основы шотландского мировоззрения, автор пробудил интерес британского общества к историческому наследию Шотландии, тем самым заложив основу успешной интеграции двух народов в единую нацию. Сэру Уолтеру Скотту своей работой удалось возродить национальный престиж Шотландии, пострадавший после подписания Унии 1707 года.

Ключевые слова: Горная Шотландия; Равнинная Шотландия; национальная идентичность; конструктивизм; этнос; религиозная идентичность; шотландская баллада; Роб Рой; пресвитерианство; Славная революция; цикл Оссиана; песни шотландской границы.

В современном социокультурном пространстве процесс формирования и трансформации национальной идентичности становится предметом изучения все большего числа исследователей, поскольку именно в национальной идентичности отражается состояние социума, его интегрированность, конформность, способность к консолидации и ценностные ориентации. Учитывая тенденцию к мировой глобализации и, как следствие, нарастающую волну сепаратизма, актуальность исследования путей и способов формирования национальной идентичности сложно переоценить. Именно осознание национальной идентичности скрывает в себе огромный потенциал для преодоления культурной разобщенности и межнациональных конфликтов.

Введение в научный оборот термина «идентичность» принадлежит выдающемуся исследователю в области социальной психологии Эрику Хомбургеру Эриксону [1, с. 23]. Также благодаря работам Э. Эриксона стало широко использоваться понятие «кризис идентичности», который возникает в условиях глубоких общественных трансформаций [2, с. 55]. Дальнейшие исследования в этой области Э. Геллнера $[3$, c. 21], Э. Хобсбаума [4], Б. Андерсона [5] выявили роль государства и интеллектуальных элит в процессе формирование как общегосударственной, так и 
этнической идентичности, которая понимается как осознание принадлежности и эмоциональной общности в политическом и общегражданском сообществе, находящемся в рамках данного государства.

Одним из важнейших условий успешного формирования национальной идентичности, по мнению выдающегося исследователя в области социальной антропологии Федерика Барта, является наличие этнических границ внутри социума, которые диктуют сложную организацию поведения. Они способствуют успешному социальному взаимодействию, так как структурируют социальную жизнь в полиэтническом обществе. В свою очередь, существование этнических границ, по мнению ученого, возможно лишь тогда, когда этническая общность наделяется значимыми, отличающими ее от остальных характеристиками, то есть культурными особенностями [6, с. 24].

В данном контексте особый интерес вызывают взгляды выдающегося этнолога Клода Леви-Стросса, который отмечал, что чем больше культуры замечают внутри друг друга различий, тем больше они находят общих точек соприкосновения в своем межкультурном диалоге. Если культуры не различаются по существу, они не притягиваются друг к другу. Исследователь считал, что чем дальше простирается взор от своей собственной культуры, тем отчетливей становится собственное «Я» и результативней жизнь в своей культурной среде. В работе «Первобытное мышление» Леви-Стросс отмечает: «Когда хочешь изучать людей, надобно смотреть вокруг себя, но чтобы изучить человека, надо научиться смотреть вдаль [7, с. 74]. И еще: «... чтобы понять современность, надо отступить хотя бы на шаг от настоящего как в пространстве, так и во времени» [8, с. 97].

Неоднократно данная концепция находила подтверждение в ходе историко-культурного развития различных этносов, регионов и государств. Одной из ярчайших страниц, иллюстрирующих парадигму конструктивистского подхода к изучению национальной идентичности, является опыт преодоления этносоциальной разобщенности Соединенного королевства на рубеже XVIII-XIX веков, во многом благодаря деятельности шотландских интеллектуалов, ярчайшим представителем которых является сэр Уолтер Скотт.

В процессе формирования национального сознания Шотландия столкнулась с проблемой национальной разобщенности как внутри этноса, так и в имперском масштабе. Пограничье и Равнинная Шотландия были ориентированы в большей степени на взаимодействие с Европой, чем на контакт с третьей областью - Хайлендом [9, с. 6]. Основное население Британии относилось с насмешкой к населению Хайленда, считая их необразованными простаками $[10$, c. 35$]$.

Еще в начале XVIII века Шотландия считалась одной из наиболее экономически отсталых стран Европы. Заключение Унии 1707 года оказало решающее значение для дальнейшего социально-экономического и политического развития Шотландии. Устраняя торгово-экономические и политические барьеры, Уния привела к ускоренному капиталистическому развитию сельскохозяйственной Шотландии.

В 1770 году Британский парламент принимает закон, по которому шотландские землевладельцы по- лучают право свободно распоряжаться землей и совершать различные земельные операции. Это создало благоприятные условия для развития капитализма в шотландской глубинке - вытеснение мелких арендаторов из сельскохозяйственного производства. В результате промышленного переворота, который совершается в Шотландии в 70-80-е годы XVIII века, происходит перемещение жителей Хайленда и Пограничья в города Центральной, Южной и СевероВосточной Шотландии, где они становятся основным резервом свободной рабочей силы. [11, с. 96115]. Именно этот период явился переломным моментом в процессе формирования шотландской национальной идентичности. Национальные черты, особенности языка, фольклор вызывали все больший интерес у широкой публики, поскольку выходцы из Хайленда и Пограничного края становились активными участниками социально-экономического взаимодействия как внутри Шотландии, так и в рамках Соединенного королевства в целом. Таким образом, учитывая все возрастающую роль шотландцев, формировался социальный запрос на знакомство с «истинно шотландским» характером, особенностями культуры, историческим наследием Великой Шотландии.

Во второй половине XVIII века возникает также политическая востребованность успешной интеграции шотландцев, так как военно-политическая угроза со стороны Хайленда была ликвидирована и, учитывая длительное противостояние между Великобританией и Францией, продолжавшееся с 1689 по 1815 гг., государственный заказ был очевиден. Соединенному королевству необходимы были рекрутышотландцы, регулярно поставляемые в армию ее Величества [12, с. 63].

Влияние как социальной, так и политической востребованности популяризации шотландской национальной культуры не могло не встретить отклика среди шотландской интеллектуальной элиты. Вальтер Скотт, будучи сыном своего народа, отчетливо осознавал, что Шотландии необходима дальнейшая интеграция в Британское содружество. Однако успешный альянс возможен лишь при соблюдении трех условий: сохранении в национальном сознании чувства «шотландскости» [13, с. 15], то есть сохранение этнического «мы», нивелировании исторически сложившегося англо-шотландского противостояния путем романтизации далекого прошлого, популяризации традиционного старинного фольклора и героической шотландской истории, а также при формировании в сознании широких масс образа доблестного шотландца, с забавными особенностями национального характера.

C середины XVIII века начинает активно изучаться наследие шотландских менестрелей, дошедшее в преданиях и старинных балладах. Наиболее интересные работы в этой области принадлежат перу Джеймса Макферсона и епископа Перси. В сборнике Макферсона - поэмах Оссиана, как замечает Б.Г. Реизов, было сделано самое главное: гэльское поэтическое мышление было переведено на английский язык. Осталось только откинуть то, что было добавлено Макферсоном в угоду его вкусам и вкусам эпохи [14, с. 78]. Однако поистине настоящим шедевром среди сборников народной шотландской поэзии яв- 
ляется вышедший в свет в 1802 году под редакцией Вальтера Скотта сборник «Песни шотландской границы».

После «Памятников» епископа Перси двухтомный (во втором издании - трехтомный) сборник Скотта «Песни шотландской границы» стал самым полным собранием народной поэзии вплоть до конца $\mathrm{XIX}$ в. В «Песнях» он проявил мастерство редактора, изучившего все издания XVI-XVIII вв. старинной английской поэзии и народных баллад. Скотт ввел гэльскую Шотландию в область высокой поэзии, и это было для английской литературы новостью большого значения [14, с. 79].

Будучи уже автором популярного сборника народной поэзии как на родине, так и во всей Британии, Вальтер Скотт в мае 1818 г. в письме Марии Эджворд замечает: «Ваша величайшая заслуга, в моих глазах, состоит в том, что вы подняли свою нацию во мнении публики и познакомили всю остальную Британскую империю с интересным и своеобразным характером народа. И я верю, что книги, которые учат ее сыновей, в чем их сила и в чем слабость, и показывают их согражданам их подлинную цену и достоинство, должны вызывать к жизни постепенные, но счастливые перемены» [15, с. 298]. Учитывая увлеченность романтической литературой своих современников, Скотт обращается к жанру исторического романа. Он пытается показать читателю англичанину путь к пониманию Шотландии, ее национальных особенностей.

Первым произведением в данном жанре, знакомящим широкую публику с национальным колоритом и особенностями шотландских нравов, является роман «Уэверли, или Шестьдесят лет тому назад».

Не случайно роман получил такое название. В послесловии к произведению Скотт отмечает, что в ходе исторического развития общество не замечает «пройденного расстояния». Современное поколение очень сильно отличается даже от предыдущего «людей старой закваски» [16, с. 594]. С потерей людей прошлых поколений утрачиваются примеры исключительной шотландской верности, гостеприимства, достоинства и благородства. Отодвигая события повествования на шестьдесят лет в прошлое, автор пытается передать ту «истинную шотландскость», которая была исконно присуща его народу.

В «Уэверли» Шотландия показана через призму мировоззрения англичанина. Это не случайно, так как идентичность формируется в процессе отнесения человеком себя к определенной социокультурной среде. Необходимым условием осуществления данного процесса является соотнесение человеком себя с определенной социокультурной общностью и противопоставление иной общности, в результаты чего в сознании читателя формируется дихотомия «мы они». Кроме того, человек должен иметь четкое представление о самой окружающей действительности, чтобы найти свое место в ней. Таким образом, Скотту уже первым романом, вышедшим из-под его пера, удалось обозначить те этнические границы внутри социума, которые способствуют, по мнению Федерика Барта, структурированию общественных отношений и консолидации полиэтнических сообществ, диктуя сложную организацию поведения. Они способствуют успешному социальному взаимо- действию, так как регулируют социальную жизнь в полиэтническом обществе. Необходимым условием успешного социального взаимодействия является наделение этнической общности значимыми, отличающими ее от остальных характеристиками, то есть культурными особенностями [17, с. 24]. Читатель, идентифицируя себя с тем или иным архетипом героя, становится участником процесса формирования «Я-образа» - базового элемента идентичности.

Также одним из важнейших элементов национальной идентичности является идеологическая составляющая - религиозное сознание народа. Известный французский философ Анри Бергсон считает, что в прошлом и даже в современности существуют общества, в которых нет ни науки, ни искусства, ни философии. Но никогда не существовало обществ, в которых не было бы религии [18, с. 12]. Именно в религиозной традиции отражается этическая константа как единичного представителя, так и этноса в целом. Религиозная основа оказывает непосредственное влияние на мировоззрение и мироощущение народа, формируя представление о добре и зле, а также ожидания в области социального взаимодействия внутри этноса и при межэтнических контактах. Именно в процессе противопоставления религиозных основ формируется образ своей духовной культуры - идеологической основы идентичности.

Религиозная основа Шотландской ментальности это пресвитерианство. Пресвитерианство в Шотландии возникло на волне протестантской реакции в 1559-1560 годах и связано с именем Джона Нокса последователя Кальвина. Одержав победу в протестантской революции в 1560 году, лидеры пресвитерианского движения начинают реформирование церковной организации, базовой идеей которой становится отказ от необходимости посредничества духовенства при общении человека с богом. После свержения Марии Стюарт в 1567 году, пресвитерианство окончательно утверждается как государственная религия Шотландии.

Не случайно Вальтер Скотт обращается к религиозной тематике в одном из выдающихся произведений английского романтизма - в романе «Пуритане». Свое отношение к пресвитерианству писатель выражает на страницах «Рассказов трактирщика». «После революции, - пишет автор, - учение, которое проповедовало это духовенство, вполне естественно и закономерно возобладало над епископством и стало национальной религией, потому что ему были свойственны мудрость, ученость и умеренность, необходимые для такого переворота...» [19, с. 18].

Именно противопоставляя две религиозные ментальности - англиканство и пресвитерианство, Вальтер Скотт пытается обозначить те идеологические основы, которые присущи как англичанам, так и шотландцам, знакомство с которыми будет способствовать взаимопониманию этносов.

Роман «Пуритане» вышел в свет в 1816 году. События, развивающиеся в романе, относятся к 16791689 гг. Это было временем не только религиозного противостояния, но и противостояния политического. Именно в этот период возникает понятие о единой стране, объединенной в 1660 г. в период реставрации Карлом II (1630-1685), потомком шотландских Стюартов. Религиозная вражда разделяла не 
только последователей англиканства и пуританизма, религиозное противостояние охватывало множество сект, распространившихся в этот период на территории объединенного королевства. Однако Скотт в романе однозначно указывает, что народные массы Шотландии в большинстве своем, будучи умеренными пресвитерианами, были опорой правительства и Британской короны [19, с. 20]. Тем самым он нивелирует и отсылает в прошлое религиозный и политический конфликт, проводя параллель между умеренными пресвитерианами, поддерживающими корону в конце XVII века, и его современниками.

Одной из основ национальной идентичности является присутствие в этническом сознании мифологемы национального героя. Особенно актуальным процесс мифологизации национальных героев становится при утрате этносом своего привычного мира и уклада, в период социальных и политических трансформаций.

В самосознании каждой нации существует три уровня мифологизации: древнейшая прамифологизация, вторичная мифологизация и неомифы. Важнейшей особенностью неомифов является взаимосвязь мифа и политики государства. Источником государственно-политической мифологизации выступает исторический опыт этноса, его национальные герои [20, с. 118-147].

Таким образом, обращение писателя к образу Роб Роя было не случайным. Шотландия нуждалась в национальном герое, не уступающем по своей популярности Робин Гуду англичан. Так, уже во введении к роману писатель в первых строках проводит аналогию между Робином Гудом и Роб Роем, уточняя, что последний проживал у самой границы Горной страны. Именно этот национальный герой, по мнению Скотта, олицетворял собой истинный дух Хайленда. Еще в январе 1812 года в письме миссис Клефан Скотт упоминает, что он стал обладателем настоящей реликвии - ружья Роб Роя, которое поместил над камином [21, с. 117].

Происхождение Роб Роя было истинно шотландским. Скотт говорит о его происхождении как о самом большом преимуществе [22, с. 5], и это не случайно. Понятие клана было священным для каждого шотландца. Сам писатель необычайно гордился своей родословной, так как происходил из рода Баклю, состоял в родстве с Мюрреями, Резерфордами, Суинтонами и Хейлибертонами, видными семействами Пограничного края. Упоминая о своих предках в ответ на просьбу Геральдической палаты набросать эскиз герба, сэр Скотт сказал: «До Унии Королевств мои предки, подобно другим джентльменам Пограничного края, триста лет промышляли убийствами, кражами и разбоем; с воцарением Иакова и до революции они участвовали в богохранимом парламентском войске, то есть лицемерили, распевали псалмы; при последних Стюартах преследовали других и сами подвергались гонениям; охотились, пили кларет, учиняли мятежи и дуэли вплоть до времен моего отца и деда» $[23$, с. 5].

Учитывая, что действия романа «Роб Рой» происходят в 1715 году, становится логичным наделение героя такими качествами, как честность в схватках, присущая горцам, понятие нравственности, сравнимое с представлениями арабского вождя. Скотт пишет: «Если бы Роб Рой стал оправдывать свой образ жизни...он, несомненно, считал себя храбрецом, которого закон лишает прирожденных прав и вынуждает отстаивать их вооруженной силой...» [24].

Таким образом, очевидно, что в своих исторических романах сэр Уолтер Скотт синтезирует и воссоздает в национальном сознании базисные элементы национальной идентичности. Национальный колорит и характер в романах нисколько не приукрашен, благодаря чему в сознании читателя, как англичанина, так и шотландца, происходит формирования образа «истинной Шотландии», а вместе с тем и обозначаются этнические границы, способствующие успешному социальному взаимодействию.

Следуя парадигме конструктивистского подхода в изучении национальной идентичности, анализируя романы великого писателя, можно выделить следующие базисные элементы формирования национальной идентичности. Во-первых, самобытность Шотландии всегда показывается через восприятие англичанина, тем самым создаются предпосылки к формированию дихотомии «мы - они», обязательного условия формирования этнического сознания. Писателю, таким образом, удалось показать сильные и слабые стороны ментальности своего народа. Вовторых, автор не оставляет без внимания идеологическую основу идентичности - религиозное сознание, отмечая, что шотландцы, умеренные пресвитериане, были всегда на стороне британской короны, тем самым нивелируя религиозное противостояние двух корон. В-третьих, Скотт воссоздает архетип национального героя - значимый элемент национальной идентичности. Проводя аналогию с истинным национальным героем англичан Робин Гудом, в образе Роб Роя автор показывает национальный дух героического народа, тем самым обозначая значимые черты шотландского этноса.

Принимая во внимание популярность исторических романов Вальтера Скотта среди современников, а также на протяжении последующих веков, становится очевидным колоссальное воздействие творчества великого автора как на формирование этнического сознания шотландцев, так и на внутриполитические и социальные процессы, протекавшие в Великобритании в конце XVIII - начале XIX века.

\section{СПИСОК ЛИТЕРАТУРЫ:}

1. Эриксон Э. Идентичность: юность и кризис. Пер. с англ. М.: Изд-во «Флинта», 2006. 342 с.

2. Эриксон Э.Г. Кризис идентичности в автобиографической перспективе (фрагмент из книги «История жизни и исторический момент», 1975) // Личность. Культура. Общество. 2008. Вып. 2. С. 48-59.

3. Геллнер Э. Нации и национализм / пер. с англ. Т.В. Бредниковой, М.К. Тюнькиной; ред. и послесл. И.И. Крупника. М.: Прогресс, 1991. 794 с.

4. Eric Hobsbawm, Terence Ranger: The Invention of Tradition. Cambridge. Cambridge University Pres 1992. $322 \mathrm{p}$.

5. Андерсон Б. Воображаемые сообщества. Размышления об истоках и распространении национализма. М.: Изд-во «КАНОН-пресс-Ц», «Кучково поле», 2001. 288 с.

6. Гражданская и религиозная идентичность: вчера, сегодня, завтра / РАН, ин-т социологии; рук. проекта и отв. ред. Л.М. Дробижева. М.: Изд-во «Росспэн», 2013. $483 \mathrm{c}$. 
7. Леви-Стросс К. Первобытное мышление / пер., вступ. ст. и прим. А.Б. Островского. М.: Изд-во «Республика», 1994. 384 с.

8. Леви-Стросс К. Мифологики: Человек голый / Перевод с французского К.З. Акопяна. М.: Изд-во «Флюид», 2007. 784 с.

9. Апрыщенко В.Ю. Клановая система горной Шотландии. Ростов-на-Дону: изд. Рост. у-та, 2006. $320 \mathrm{c}$.

10. The Scottish Highlanders and the Land Lawsan Historico-economical enquiry / Johr Blackie F.R.S.E. London. 1885, 215 p.

11. Зверева Г.И. История Шотландии. М.: Изд-во «Высшая школа», 1987. 208 с.

12. Малкин С.Г. Горная Шотландия конца XVII первой половины XVIII века и романы Вальтера Скотта // Новая и новейшая история. № 2, 2010. C. $59-71$.

13. Апрыщенко В.Ю. Уния и модернизация: становление шотландской национальной идентичности в XVIII - первой половине XIX в.: автореф. дис. ... д-ра ист. наук. Ростов-на-Дону, 2009. 35 с.

14. Реизов Б.Г. Творчество Вальтера Скотта. М.: Изд-во «Художественная литература», 1965. 498 с.
15. Переписка Марии Эджворт и Вальтера Скотта / М. Эджворт. Замок Рэкрент. Вдали отечества. М.: Изд-во «Наука», 1972. 350 с.

16. Скотт В. Собрание сочинений в 20 т. Т. 1. Уэверли. М.: Изд-во «Художественная литература», $1960.639 \mathrm{c}$

17. Гражданская и религиозная идентичность: вчера, сегодня, завтра / отв. ред. Л.М. Дробижева. М.: Изд-во «Росспэн», 2013. 483 с.

18. Бергсон А. Два источника морали и религии. М.: Изд-во «Канон», 1994. 384 с.

19. Скотт В. Пуритане. М.: Изд-во «Художественная литература», 1989. 324 с.

20. Шнирельман В.А. Национальные символы, этноисторические мифы и этнополитика // Теоретические проблемы исторических исследований. М.: МГУ, 1999. Вып. 2. С. 118-147.

21. The letters of Sir Walter Scott / Ed. by H. Grierson, D. Cook and W. Parker. Vol. 1-12. Vol. 3 Lnd.: Constable, 1932-37.

22. Скотт В. Роб Рой. М.: Изд-во «Дом», 1992. $215 \mathrm{c}$.

23. Пирсон Х. Вальтер Скотт. М.: Изд-во «Терра», 2003. $204 \mathrm{c}$

\title{
THE HISTORICAL NOVELS OF SIR WALTER SCOTT - THE SUBSTANTIAL FACTOR IN THE FORMATION OF SCOTTISH NATIONAL IDENTITY AT THE TURN OF XVIII-XIX CENTURIES
} (C) 2017

Fedorova Tatyana Alexandrovna, postgraduate student of General History, Law and Methods of Teaching Department Samara State University of Social Sciences and Education (Samara, Russian Federation)

Abstract. The paper discusses the influence of Walter Scott's historical novels on the formation of national identity of Scotland at the turn of the eighteenth to early nineteenth centuries. In the current geopolitical situation, considering the growing wave of separatism, the relevance of the study of national identity formation process cannot be overemphasized. In the paper the author analyzes the historical preconditions of Scots national consciousness formation. The author also considers characteristics of historical and cultural development of the region. According to the author, James MacPherson and Bishop Percy's works were equally important for national disunity overcoming in Scotland and Britain as a whole. Particular attention is drawn to the role of Sir Walter Scott in the process of national revival in Scotland. Such novels as «Waverley», «Puritans», and «Rob Roy» introduced the general public with the mental basis of the Scottish people. Having opened national character features and religious foundations of the Scottish worldview for a wide range of readers, the author awakened the interest of the British society to the heritage of Scotland, thereby laying the basis for a successful integration of the two peoples into a single nation. Sir Walter Scott managed to revive national prestige of Scotland that had fallen victim after the signing of Union in 1707.

Keywords: highlands; Lowland Scotland; national identity; constructivism; ethnicity; religious identity; Scottish ballad; Rob Roy; Presbyterian; Glorious revolution; cycle of Ossian; Songs of Scottish borders.

УДК 94(394)

\section{ДУХОВНАЯ И ОБРАЗОВАТЕЛЬНАЯ ДЕЯТЕЛЬНОСТЬ ТАТАР В КАЗАХСКОЙ СТЕПИ В КОНТЕКСТЕ ВНУТРЕННЕЙ ПОЛИТИКИ РОССИЙСКОЙ ИМПЕРИИ (ВТОРАЯ ПОЛОВИНА ХVІІІ - НАЧАЛО ХХ ВЕКА)}

(C) 2017

\author{
Махмутов Зуфар Александрович, кандидат исторических наук, \\ старший научный сотрудник отдела этнологических исследований \\ Институт истории им. Ш. Марджани Академии наук Республики Татарстан \\ (г. Казань, Российская Федерачия)
}

\footnotetext{
Аннотащия. В данной статье рассматривается духовная и образовательная деятельность татар в казахской Степи в дореволюционное время. Императрица Екатерина II положила начало массовому проникновению в Степную зону татарских мулл, которые помимо религиозной и образовательной деятельности также исполняли некоторые функции царских чиновников: вели метрические книги и гражданское судопроизводство. Татарский язык стал основным языком делопроизводства в Степной зоне. После Крымской и Кавказской
} 